IZA DP No. 5795

Fat Chance! Obesity and the Transition from Unemployment to Employment

Marco Caliendo

Wang-Sheng Lee

June 2011 


\title{
Fat Chance! \\ Obesity and the Transition from Unemployment to Employment
}

\author{
Marco Caliendo
}

$I Z A, I A B$ and DIW Berlin

Wang-Sheng Lee

RMIT University and IZA

\section{Discussion Paper No. 5795 \\ June 2011}

\author{
IZA \\ P.O. Box 7240 \\ 53072 Bonn \\ Germany \\ Phone: +49-228-3894-0 \\ Fax: +49-228-3894-180 \\ E-mail: iza@iza.org
}

\begin{abstract}
Any opinions expressed here are those of the author(s) and not those of IZA. Research published in this series may include views on policy, but the institute itself takes no institutional policy positions.

The Institute for the Study of Labor (IZA) in Bonn is a local and virtual international research center and a place of communication between science, politics and business. IZA is an independent nonprofit organization supported by Deutsche Post Foundation. The center is associated with the University of Bonn and offers a stimulating research environment through its international network, workshops and conferences, data service, project support, research visits and doctoral program. IZA engages in (i) original and internationally competitive research in all fields of labor economics, (ii) development of policy concepts, and (iii) dissemination of research results and concepts to the interested public.
\end{abstract}

IZA Discussion Papers often represent preliminary work and are circulated to encourage discussion. Citation of such a paper should account for its provisional character. A revised version may be available directly from the author. 


\section{ABSTRACT \\ Fat Chance! \\ Obesity and the Transition from Unemployment to Employment}

This paper focuses on estimating the magnitude of any potential weight discrimination by examining whether obese job applicants in Germany get treated or behave differently from non-obese applicants. Based on two waves of rich survey data from the IZA Evaluation dataset, which includes measures that control for education, demographic characteristics, labor market history, psychological factors and health, we estimate differences in job search behavior and labor market outcomes between obese/overweight and healthy weight individuals. Unlike other observational studies which are generally based on obese and nonobese individuals who might already be at different points in the job ladder (e.g., household surveys), in our data, individuals are newly unemployed and all start from the same point. The only subgroup we find in our data experiencing any possible form of labor market discrimination is obese women. Despite making more job applications and engaging more in job training programs, we find some indications that they experienced worse (or at best similar) employment outcomes than healthy weight women. Obese women who found a job also had significantly lower wages than healthy weight women.

JEL Classification: I10, I12, J23, J70

Keywords: obesity, discrimination, employment, labor demand

Corresponding author:

Wang-Sheng Lee

School of Economics, Finance and Marketing

RMIT University

Level 12

239 Bourke Street

Victoria 3000

Australia

E-mail: wangsheng.lee@rmit.edu.au

\footnotetext{
* The authors would like to thank Dan Hamermesh, seminar participants at RMIT University and Queensland University of Technology, and conference participants at the 3rd IZA Annual Conference on the Economics of Risky Behaviors for helpful comments and suggestions. The IAB (Nuremberg) kindly gave us permission to use the administrative data.
} 


\section{Introduction}

Obesity has recently emerged as a prevalent problem in many developed countries. For example, between the periods 1976-1980 and 1999-2000, the prevalence of overweight ( $\mathrm{BMI} \geq 25$ ) persons in the US increased from $46 \%$ to $65 \%$, and the prevalence of obesity (BMI $\geq 30$ ) increased from 15\% to 31\% (Flegal et al., 2002). ${ }^{1}$ By 2007-2008, the prevalence of obesity had further increased to $32.2 \%$ among adult men and 35.5\% among adult women (Flegal et al., 2010). Similarly in Europe, the prevalence of obesity in men ranged from $4.0 \%$ to $28.3 \%$ and in women from $6.2 \%$ to $36.5 \%$ during the period 1980-2005. Eastern Europe and the Mediterranean countries showed higher prevalences of obesity than countries in Western and Northern Europe (Berghöfer et al., 2008). The alarming rise of obesity over the years has led to the practice of a new form of discrimination that has received relatively little attention in the economics literature - weight discrimination.

Researchers estimate that at present, weight discrimination is comparable to rates of race and age discrimination, especially among women. In 1995-96, weight discrimination was reported by $7 \%$ of US adults. In 2004-2006, that percentage rose to $12 \%$ of adults (Andreyeva et al., 2008). Puhl and Brownell (2001) published the first comprehensive review of several decades of research documenting bias and stigma toward overweight and obese persons. Their review summarized weight stigma in domains of employment, health care, and education, demonstrating the vulnerability of obese persons to many forms of unfair treatment. It highlighted that weight discrimination is rampant in the workplace, health care and education arenas. Based on data from the National Survey of Midlife Development in the US, a nationally representative sample of adults aged 25-74 years, Roehling et al. (2007) found that overweight respondents were 12 times more likely, obese respondents were 37 times more likely, and severely obese respondents were 100 times more likely than normal-weight respondents to report employment discrimination. In addition, women were 16 times more likely to report weight-related employment discrimination than men. A meta-analysis of 32 experimental studies which investigated weight discrimination in employment settings was recently conducted by Roehling et al. (2008). Typically, such experimental studies ask participants to evaluate a fictional applicant's qualifications for a job, where his or her weight has been manipulated

\footnotetext{
${ }^{1}$ Body mass index (BMI) is the ratio of weight measured in kilograms, to squared height measured in meters.
} 
(through written vignettes, videos, photographs or computer morphing). Outcome variables examined in these studies included hiring recommendations, qualification/suitability ratings, disciplinary decisions, salary assignments, placement decisions, and co-worker ratings. Across studies, it was demonstrated that overweight job applicants and employees were evaluated more negatively and had more negative employment outcomes compared to non-overweight applicants and employees.

This paper focuses on examining whether newly unemployed and obese job applicants in Germany get treated or behave differently from non-obese applicants. Despite evidence that obese people experience discrimination, to date, with the exception of the state of Michigan in the US, which enacted a law in 1977 prohibiting discrimination against overweight people, there are no laws protecting overweight people from discrimination in employment, education, and health care. In Germany, the 2006 General Equal Treatment Act (Allgemeines Gleichbehandlungsgesetz) was introduced only after a long and controversial legislative procedure. This was intended to be a combination of four EU Equality Directives (2000/43, 2000/78, 2002/73 and 2004/113) and prohibits discrimination based on race or ethnical origin, religion or belief, sex, disability, age or sexual orientation. This paper examines more closely whether these new laws had any effects on the outcomes of obese unemployed Germans in 2007-2008. ${ }^{2}$ In addition to observing the employment outcomes of job applicants, a novel feature of our data set is that we also have information on the search behavior of job applicants. We therefore will be given insights as to whether any observed differences in labor market outcomes have arisen because one group simply was less motivated or tried less hard to look for a job, or possibly because they had different access to labor market training programs.

To preview our findings, we find that overweight men, obese men and overweight women experience no discrimination in terms of access to programs that are part of active labor market policies (ALMP) or in their employment and wage outcomes. The only group we find in our data experiencing any possible form of labor market discrimination is obese women. Despite making more job applications and engaging more in job training programs, we find some indications that they experienced worse (or at best similar) employment outcomes than healthy weight

\footnotetext{
${ }^{2}$ Discrimination against the obese is not explicitly mentioned in the 2006 Act but the new antidiscrimination culture in Germany could plausibly have indirect effects on them.
} 
women. Obese women who found a job also had significantly lower wages than healthy weight women.

The rest of this paper is organized as follows. Section 2 describes the data in more detail. Section 3 provides more background and discusses some theoretical motivations, whereas Section 4 presents the methods used. The empirical results are provided in Section 5. Finally, Section 6 concludes.

\section{Data}

The IZA-Evaluation Dataset is an ongoing data collection process which is specifically designed to shed more light on the transition process from unemployment to employment (see Caliendo et al., 2011, for details). It consists of two components, an administrative part as well as an additional survey data set. The sampling is restricted to individuals who are 16 to 54 years old, and who receive or are eligible to receive unemployment benefits under the German Social Code III. The administrative part covers a random inflow sample into unemployment for the years 2001-2008 containing over 920,000 individuals. Administrative records are based on the 'Integrated Labour Market Biographies’ of the Institute for Employment Research (IAB), containing relevant register data from four sources: employment history, unemployment support recipience, participation in active labor market programs, and job seeker history. For the complementary survey a random sample of individuals who entered unemployment between June 2007 and May 2008 is chosen. From the monthly unemployment inflows of approximately 206,000 individuals in the administrative records, a 9\% random sample is drawn which constitutes the gross sample. Out of this gross sample each month representative samples of approximately 1,450 individuals are interviewed, so that after one year 12 monthly cohorts are gathered. The key feature of the data set is that individuals are interviewed shortly after they become unemployed and are asked a variety of non-standard questions. In addition to measuring an extensive set of individual-level characteristics and labor market outcomes, a particular strength of the survey dataset is that it contains many non-standard, innovative questions including search behavior, social networks, psychological factors, cognitive and non-cognitive skills, subjective assessments on future outcomes, and attitudes. As will be discussed in a later section, such rich micro-level data are important in helping us identify the effects of obesity on labor market outcomes using decomposition and matching approaches. 
For the purposes of this paper, we focus on three cohorts of the survey dataset (June 2007, October 2007 and February 2008) in which data on height and weight were collected. For these three cohorts, two waves of data are available and analyzed in this paper. In wave 1 , the initial interviews were conducted close to the unemployment entry. Wave 2 was conducted one year after entry into unemployment. Our analysis sample comprises of the 784 men and 673 women who responded to both waves 1 and 2 of the survey; out of these 401 men and 438 women were still unemployed and actively searching for a job in wave 1.

This paper uses body mass index (BMI) as our measure of body size, which is based on self-reported weight in kilograms divided by self-reported height in meters squared. According to widely used classifications by the U.S. National Institutes of Health, an individual who has a BMI below 18.5 is underweight; one whose BMI is between 18.5 and 25 is healthy weight; one whose BMI is between 25 and 30 is overweight; and one whose BMI is over 30 is obese. ${ }^{3}$ Table 1 displays the sample sizes of men and women in each of the BMI categories in our data set. Note that as there are very few individuals with BMI values below 18.5, we omit this group of individuals when performing any further analysis in this paper.

* Table 1 about here *

Table 2 provides some descriptive statistics regarding the socio-demographic characteristics of individuals who are of normal weight, overweight and obese. These descriptive statistics indicate that there are different types of men and women in each of the groups and that naively comparing outcomes across groups will not yield any informative insights. For example, obese men tend to be on average older (38.28 years) than overweight men (36.32 years) or healthy weight men (31.07 years). Similarly, obese women tend to be older than overweight women who are in turn older then healthy weight women too, where the average ages are 40.92, 38.14 and 35.70 respectively. In terms of education, it can be seen that a larger proportion of healthy weight men had technical college or university degrees as compared to obese

\footnotetext{
${ }^{3}$ Although BMI is not an optimal measure of obesity because it is unable to distinguish between lean body mass and body fat (e.g., Burkhauser and Cawley, 2008; Johansson et al., 2009), it is the only measure of obesity available in this data set.
} 
men (0.24 vs. 0.21). This difference was more pronounced when comparing healthy weight women and obese women (0.32 vs. 0.18).

As can be seen in Table 2, we also control for labor market history using several different measures. Importantly, we observe whether individuals receive unemployment benefits and the level of benefits. Since benefits in Germany are directly related to previous net income, this should give us a good approximation also of the unobservable variables potentially influencing employment outcomes. Additionally, we also observe the number of months individuals spent in employment and unemployment over their lifetime and later use this information adjusted for age in our regression models. Finally, we also have information on the employment status of the individuals just before they become registered as unemployed, e.g., whether they have been in paid-employment, self-employment, subsidized employment or school.

* Table 2 about here *

Table 2 also examines group differences in personality traits and health. With regards to personality characteristics, it can be seen that obese men and women have lower values for their internal locus of control, which suggest that obese persons are more likely to believe that fate or chance primarily determine their life events and destiny. Another main difference that can be seen is with regards to health, where obese men and women are more likely than non-obese men and women to have bad general health and a physical impairment in the last two months.

\section{Obesity and labor market outcomes}

Active labor market policies in Germany aim to reintegrate unemployed individuals into the labor market. Active and passive labor market policies have been reformed substantially between 2003 and 2005 within the 'Hartz-reforms', where the reforms touched the core elements of the labor market, the organizational structure of the labor offices as well as the pension system. As a general goal, the reforms aimed at increasing incentives to take up work (see Eichhorst and Zimmermann, 2007, for an overview). One of the most substantial parts of the welfare reform (Hartz IV) took 
place in the beginning of $2005 .{ }^{4}$ Much research has focused on examining the effects of different types of training programs - affecting the labor supply side of the market - on individual employment outcomes. ${ }^{5}$ However, considerable less attention has been placed on the demand side of the market. How do employers decide whom to hire from a pool of unemployed workers? What factors affect how long they are hired for?

Given the tendency for obesity to be strongly associated with low socioeconomic status (e.g., Brunello et al., 2009) and the interest in helping the unemployed transition from unemployment to employment, in addition to job training programs that aim in helping individuals improve their human capital, considerable attention has been put on identifying potential barriers to employment on the supply side. For example, Danziger et al. (2000), Jayakody and Stauffer (2000), and Corcoran et al. (2004) examine a variety of mental and physical health barriers that reduce the probability of labor market success. Considerable less research has been devoted to another potential barrier to employment - obesity. With the exception of Cawley and Danziger (2005), we are not aware of any other study that focuses on obesity as a barrier in helping welfare recipients transition from welfare-to-work.

A correlation between body weight and labor market outcomes could arise for several reasons. As Cawley (2004) notes, the first explanation is that obesity lowers wages. This explanation consists of both demand and supply side factors. On the supply side, obesity may impair one’s ability to work through having poor health or low self-esteem. In addition, obese persons may be less motivated to invest in their own human capital. For example, obese persons might place a higher premium on present consumption and satisfaction and be less concerned about longer term health consequences. They could therefore also plausibly be less likely to engage in activities like training, which only have payoffs in the more distant future. On the demand side, there could be discrimination by employers. This might arise from

\footnotetext{
${ }^{4}$ Jacobi and Kluve (2007) provide a detailed survey of the reform package. Under Hartz IV, for the first time, extensive efforts were made to reintegrate welfare recipients into the labor market. Recipients were required to participate in welfare to work programs, and were subject to sanctions for non-compliance or rejection of suitable job offers. In these respects, the Hartz IV reform shares many similarities with the 1996 Personal Responsibility and Work Opportunity Act (PRWORA) in the U.S., which required most welfare recipients to seek employment.

${ }^{5}$ For example, Card et al. (2009) perform a meta-analysis of 97 studies conducted between 1995 and 2007 and find that in general, job search assistance programs have relatively favorable short-run impacts, whereas classroom and on-the-job training programs tend to show better outcomes in the medium-run than the short-run.
} 
employers being prejudiced against the obese and having a distaste for working or dealing with them; from employers stereotyping obese workers and thinking that they are less productive; or having a higher uncertainty or a lack of knowledge about the productivity of obese workers. The second explanation is that low wages or unemployment help cause obesity (i.e., the case of reverse causality). This would be true if poorer people consume cheaper food high in fat content. The third explanation is that there could be unobserved variables that are correlated with both obesity and employment (e.g., individual time preference).

There is a small literature in economics that examines the effects of obesity on employment and wages (e.g., Register and Williams, 1990; Loh, 1993; Sargent and Blanchflower, 1994; Pagan and Davila, 1997; Harper, 2000). More recent studies in this literature have paid more attention to controlling for the possible endogeneity of obesity with employment and wages using instrumental variable (IV) approaches (e.g., Cawley, 2004; Cawley et al., 2005; Brunello and D’Hombres, 2007; Morris, 2007; Lindeboom et al., 2010). In addition, lagged body weight has been used in place of current body weight in order to avoid the influence of wages on contemporaneous weight (e.g., Conley and Glauber, 2006). Fixed effects models have also been used to eliminate the influence of time-invariant unobserved heterogeneity on weight and wages (e.g., Averett and Korenman, 1996). These studies generally tend to find that obese women earn less than healthy-weight women.

As Garcia and Quintana-Domeque (2006), Cawley (2007) and Lindeboom et al. (2010) note, however, establishing convincing causal effects of obesity is not easy. For example, it appears that a plausible instrument for obesity is to use the BMI of a family member. But there is a possibility that a substantial part of the genes responsible for obesity are also responsible for other factors that affect labor market success.

Experiments provide one convincing way of estimating the causal effects of obesity. Adopting a field experiment approach, Rooth (2009) identifies differences in labor market outcomes due to obesity that can be interpreted as causal. He achieves this by weight manipulation of facial photographs attached to job applications. The basis for conducting such an experiment comes from lab settings in which psychologists and sociologists have been documenting systematic differential treatment by employers against obese applicants (e.g., see Roehling, 1999). In his experiment, Rooth (2009) sent two equivalent applications to advertised job openings 
with the only difference being that one has a picture of a person with normal weight and the other has a digitally modified picture to make the same person look obese. A key advantage of this approach is that it helps ensure that other supply side characteristics of the job applicant are held constant. However, a disadvantage of field experiments of this nature is that it focuses on callback rates or offers for an interview, and not the actual event of being offered a job. ${ }^{6}$

Given the difficulties in plausibly estimating a causal effect of obesity when an experimental design is not feasible, as an alternative, it is possible to perform an accounting exercise and simply focus on estimating the magnitude of the raw and conditional gap in outcomes between obese and non-obese individuals. In this case, the focus is not on estimating average treatment effects but instead on a more general issue - estimating the magnitude of any potential discrimination that might lead to obese job applicants being treated or behaving differently from non-obese applicants. Here, decomposition approaches can be used to distinguish between explained and unexplained components of the gap that is observed between obese and non-obese individuals.

\subsection{Discrimination against the obese - a theoretical perspective}

Employers might choose not to hire obese persons due to widespread negative stereotypes that overweight and obese persons are lazy, unmotivated, lacking in selfdiscipline, less competent, noncompliant, and sloppy (Puhl and Brownell, 2001). Is there an economic rational basis for such discrimination?

Statistical discrimination is said to occur when rational decision makers use aggregate group characteristics to evaluate individuals with whom they interact. As a result, individuals belonging to different groups may be treated differently even if they share identical observable characteristics in every other respect. The basic premise of statistical discrimination is that firms have limited information about the skills and turnover propensity of applicants, particularly workers with little labor market history. As such, firms have an incentive to use easily observable group

\footnotetext{
${ }^{6}$ In addition to responding to job vacancies using written job applications, approaches using actual persons who pretend to have similar qualifications except for the variable of interest (race, gender etc.) have also been used. The advantages and disadvantages of these 'audit tests' are discussed in more detail in Riach and Rich (2002), who provide a broad survey of such field experiments of discrimination.
} 
characteristics to 'statistically discriminate' among workers if these characteristics are correlated with performance (e.g., Altonji and Blank, 1999).

Several theoretical models of statistical discrimination developed in the economics literature suggest why there could be discrimination by employers against the obese. In his seminal work on discrimination, Becker (1957) assumes that some agents have a 'taste' for discrimination. Employers taste for discrimination affects profits through wages and hiring decisions. An implication of Becker's model is that preferential hiring occurs - employers are less likely to hire obese workers of identical productivity.

Alternatively, information problems are fundamentally important in labor markets. When firms are uncertain about the true abilities and effort levels of prospective employees, it is common to turn to group identification as a signal of underlying productivity. The statistical discrimination model in Aigner and Cain (1977) highlights the type of discrimination that can occur when there is a higher uncertainty about the productivity of obese workers. The model posits two groups of individuals with known normal distributions of productivity. Although the population distribution of productivities is known, the actual productivity of any given worker is unobservable to firms. Instead, firms only observe a noisy signal of productivity, $s=\mu+\varepsilon$ where $\varepsilon$ is $N\left(0, \sigma_{\varepsilon}^{2}\right)$. Assuming that the signal is noisier for the obese than the non-obese, and that firms are risk-averse, Aigner and Cain (1977) show that the group with a noisier signal will receive lower average wages. This is because with risk aversion, wages depend not only on the conditional expectation of productivity but also on the conditional variance of productivity. As a result, hiring rates are different across groups even though productivity might be the same.

Theoretical models of discrimination attempt to rationalize discrimination. However, one must also be willing to concede that economic theory cannot fully explain the long run existence of discrimination. As Arrow (1998) notes, "[i]t is natural to suppose that economic analysis can cast light on the economic effects of discrimination. But can a phenomenon whose manifestations are everywhere in the social world really be understood, even in only one aspect, by the tools of a single discipline?” (p. 91). Darity and Mason (1998) also cast a negative light on the ability of economic theory to account for discrimination: "Since Becker's work, orthodox microeconomics has been massaged in various ways to produce stories of how 
discrimination might sustain itself against pressures of the competitive market. The tacit assumption of these approaches has been to find a way in which discrimination can increase business profits, or to identify conditions where choosing not to discriminate might reduce profits” (p. 82).

\subsection{Discrimination against the obese - a practical perspective}

In this section, we turn to factors that are outside the scope of economic theory that might help account for discrimination against the obese. Some empirical evidence in the literature suggests that there might be logical reasons why employers choose not to employ the obese. Finkelstein et al. (2005) report that obesity results in significant increases in medical expenditures and absenteeism among full-time employees. They estimate that the costs of obesity (excluding overweight persons) at a firm with 1000 employees are approximately US\$285,000 per year. Cawley et al. (2007) found that obese women were 61 percent more likely to miss work time, compared to women of healthy weight. For morbidly obese women (BMI 40 or higher), the figure rose to 118 percent. For women, obesity was linked to absenteeism across all occupational categories. For men, the relationship varied by occupation. For example, the likelihood of missed work time among men in professional and sales occupations increased along with weight category. In other occupations - including managers, office workers, and equipment operators - the risk of missed work time increased only for morbidly obese men. Taken as a whole, Cawley et al. (2007) found that obesity and morbid obesity was associated with increased rates of work absenteeism, with an estimated cost of $\$ 4.3$ billion (2004 dollars) in the US.

However, the results of these studies need to be interpreted carefully. Due to weight discrimination in health care, overweight patients might be reluctant to seek medical care, be more likely to cancel or delay medical appointments, or put off important preventative health care services. Viewed in this light, higher absenteeism amongst the obese might be the result of discrimination and should not be used to justify discrimination. In section 5, we test to see if health is an important channel by which the effects of obesity operate. We do so by estimating the obesity gap with and without health variables included. If health is an important mediating variable, we expect to see any gap between obese and non-obese persons to become smaller when health variables are controlled for. 


\section{Methodology}

This paper uses a pooled linear decomposition approach to estimate the gap in labor market outcomes between obese and healthy weight persons, as well as between overweight and healthy weight persons. As we explain below, the approach we use is closely related to the estimation of average treatment effects. The main difference is that the assumptions we invoke using the decomposition approach are weaker than the assumptions underlying the estimation of causal effects.

\subsection{Linear decomposition}

A common approach employed in the literature to distinguish between explained and unexplained components is to perform a linear decomposition, based on the seminal papers of Blinder (1973) and Oaxaca (1973). In the standard BlinderOaxaca (BO) decomposition, separate regressions are estimated for group A $\left(Y_{i}=\beta_{A} X_{i}+\varepsilon_{i}\right)$ and for group B $\left(Y_{i}=\beta_{B} X_{i}+\varepsilon_{i}\right)$, where $X$ are individual level characteristics that help explain differences in $Y$. The average gap in outcomes $\left(\bar{Y}_{A}-\bar{Y}_{B}\right)$ can be expressed as the sum of two components: $\beta_{A}\left(\bar{X}_{A}-\bar{X}_{B}\right)+\left(\beta_{A}-\beta_{B}\right) \bar{X}_{B}$. The first part is attributed to differences in average characteristics between the two groups. The second part is due to differences in average returns to the individual characteristics, which may reflect discrimination. $\beta_{A} \bar{X}_{B}$ represents the outcome for group B if they were treated as if they were members of group A. It also represents the outcome for members of group A, if they had the average characteristics of members of group B. An equally valid decomposition is to express the components of the gap as: $\beta_{B}\left(\bar{X}_{A}-\bar{X}_{B}\right)+\left(\beta_{A}-\beta_{B}\right) \bar{X}_{A}$. Many papers acknowledge this by reporting the results of both decompositions, as well the decompositions from a pooled regression without group specific intercepts based on a suggestion by Neumark (1988).

It is worth thinking carefully about what various types of BO decompositions measure precisely. Closely related to the literature on decomposition and the estimation of the size of unexplained gaps is the literature on treatment effects. When performing a decomposition, one controls for as many possible relevant covariates as possible, calling the remaining group difference unexplainable or a gap. Similarly, when estimating causal effects, one also controls for as many relevant covariates as 
possible in order to make the treatment and control groups as similar as possible. The remaining difference between the groups is then referred to as the average treatment effect. Their close relationship is immediately obvious when one simply substitutes the term 'treatment effect' for the term 'unexplained gap' in a regression framework.

Developments in the program evaluation literature have been very useful in helping clarify different parameters of interest one might be interested in estimating, and helping spell out what the two equally valid versions of the $\mathrm{BO}$ decomposition accomplish. In the first instance when the average gap is expressed as: $\beta_{A}\left(\bar{X}_{A}-\bar{X}_{B}\right)+\left(\beta_{A}-\beta_{B}\right) \bar{X}_{B}$, the focus is on members of group A and we consider the hypothetical situation of what happens if they had the average characteristics of members of group B. Renaming group $\mathrm{A}$ as the treatment group and group $\mathrm{B}$ as the control group, we can see that this decomposition is closely related to the parameter of interest known as the average treatment on the treated (ATT). On the other hand, in the opposite case where the focus is on members of group B and we think about what happens if they had the average characteristics of members of group $A$, the parameter being estimated is the average treatment on the untreated (ATUT).

Recently, Elder et al. (2010) suggest that the pooled BO decomposition without a group-specific indicator should not be used to distinguish between explained and unexplained gaps. They instead suggest the coefficient on a group indicator from an OLS regression for obtaining a single measure of the unexplained gap, and discuss how this coefficient can essentially be viewed as a weighted average of the two different ways of doing a BO decomposition. ${ }^{7}$

Estimating gaps using the OLS approach has been applied to the measurement of union wage premiums (e.g., Lewis, 1986), racial test score gaps (e.g., Fryer and Levitt, 2004), and racial wage gaps (e.g., Neal and Johnson, 1996). More recently, Lundborg et al. (2010) adopt this approach in decomposing the wage gap between obese and non-obese individuals.

\footnotetext{
${ }^{7}$ A parallel discussion of this issue can be found in Angrist and Pischke (2008) when discussing the different causal parameters that matching and OLS estimate. They note that whereas matching uses the distribution of covariates among the treated to weight covariate specific estimates into an estimate of the ATT, regression produces a variance weighted average of these effects. What this translates into is that while the ATT estimate places most weight on covariate cells containing those who are most likely to be treated, regression places most weight on covariate cells where the conditional variance of treatment status is largest, which occurs where there are equal number of treatment and control observations (Angrist and Pischke, 2008, p.76).
} 
An important advantage of viewing our problem as a decomposition problem rather than a treatment effects problem is that we can focus on the relative importance of different sets of variables in explaining the observed gap. This can be accomplished by estimating various OLS models using different combinations of characteristics. On the other hand, a treatment effects approach would focus on providing a single 'best' estimate of the impact of obesity. Importantly, the decomposition approach also does not require us to make the conditional independence assumption (CIA) underlying regression or matching estimators that attempt to measure causal effects. ${ }^{8}$

In our paper, we therefore mainly focus on applying the pooled regression decomposition approach in order to determine the relative importance of education, demographic characteristics, psychological factors and health in explaining the obesity gap among unemployed Germans. Since previous studies have sometimes observed differences in the effect of body size on the wages of men and women (e.g., Averett and Korenman, 1999; Baum and Ford, 2004; Cawley, 2004), we provide estimates separately for men and women. In addition to estimating gaps between the obese (BMI $\geq 30)$ and persons of healthy weight $(18.5 \leq \mathrm{BMI}<25)$, we also conduct similar decomposition exercises for comparing persons who are overweight $(25 \leq$ $\mathrm{BMI}<30$ ) with persons of healthy weight.

\subsection{Matching}

An alternative approach we adopt to estimate the gap in labor market outcomes between obese and non-obese persons is to use an approach from the treatment effects literature - matching. Utilizing the matching estimator as a tool to perform decompositions instead of estimating average treatment effects is similar in spirit to the papers by Nopo (2008) and Frölich (2007). Unlike in the standard application of matching in the evaluation literature, when matching is used to perform a decomposition, it is not necessary that the CIA holds. Any observable that is not measured simply falls into the residual term.

In this paper, we report our matching estimates based on kernel matching. One major advantage of kernel matching is the lower variance which is achieved because more information is used for constructing counterfactual outcomes. This could be

\footnotetext{
${ }^{8}$ This assumption states that conditional on some set of covariates, the potential outcomes for the obese and non-obese are independent of their group status. In practice, unless a rich set of covariates are available that are related to both labor market outcomes and obesity, it can be difficult to fulfil this assumption.
} 
important as our groups of obese and non-obese persons are rather small. An additional advantage of kernel matching comes from the results of Heckman, Ichimura, and Todd (1998) who derive the asymptotic distribution of these estimators and show that bootstrapping is valid to draw inference for this matching method. This allows us to circumvent the issues raised by Abadie and Imbens (2008), pointing out that bootstrap methods are invalid for nearest neighbor matching.

Before applying kernel matching, assumptions have to be made regarding the choice of the kernel function and the bandwidth parameter $h$. The choice of the kernel appears to be relatively less important in practice. What is seen as more important is the choice of the bandwidth parameter $h$ where a trade-off between a small variance and an unbiased estimate of the true density function arises (see the discussion in Caliendo and Kopeinig, 2008). We test the sensitivity of the results with respect to different bandwidth choices.

We provide matching estimates as a robustness check for several reasons. In addition to estimating a different parameter, a semi-parametric matching approach differs from the parametric BO decomposition approach in two other aspects. First, the regression function is no longer specified as linear. Second, the adjusted mean labor market outcome is simulated only for the common support subpopulation. While this latter issue is largely recognized in the program evaluation literature, it has until recently not received much attention in decomposition analysis. For example, by not considering the common support restriction, the $\mathrm{BO}$ decomposition is implicitly based on linear extrapolation and an 'out-of-support assumption'. Put another way, it becomes necessary to assume that the linear estimators of the outcomes are also valid out of the support region of individual characteristics for which they were estimated.

\section{Results}

We examine the gap between overweight and healthy weight persons, and the gap between obese and healthy weight persons on three sets of outcomes variables. The first set relates to the job search process of the unemployed individuals in wave 1 where we observe: (i) the reservation wage and (ii) the search intensity (measured as the number of job applications). As we observe these outcomes only for individuals still unemployed and actively searching for work in wave 1, the sample size for these outcomes is smaller than for the second set of outcomes which relate to participation in ALMP programs. Here, we distinguish between three outcome variables. The first 
outcome is participation in any ALMP program within the period of registering oneself as unemployed and the wave 2 interview. To determine if there are differences with respect to participation in human-capital enhancing training programs, we consider participation in training programs as a second outcome variable. Finally, to test whether there are timing differences in the participation patterns for obese and non-obese individuals, we also consider participation in the first six months after registering oneself as unemployed ('early participation') as an outcome variable. The third set of outcomes is from wave 2 and includes the employment status and the realized wage for those who have a job. We employ OLS models for all outcomes except for cases where the outcome is binary. For models with binary outcomes such as employment or participation in ALMP/training programs, we employ probit models and report marginal effects at the mean values of the covariates. All estimations are conducted separately by gender.

Table 3 presents estimates of the gap in outcomes between overweight and healthy weight men. The column labelled 'raw gap' is the unadjusted mean difference in outcomes between the two groups, where it can be seen that significant differences exist for log reservation wages in wave 1 and employment status in wave 2 . This implies that overweight men are likely to have higher reservation wages than healthy weight men, and are also more likely to be employed in wave 2. Columns (1) to (4) each control for different sets of characteristics in order to determine how each of the characteristics affect the obesity gap. Column (5) includes education, sociodemographic and personality variables in a single regression. Column (6) includes all the characteristics in column (5) with the further addition of health variables. The employment history variables in the 'other demographics' category are useful in trying to control for the labor supply of individuals in the two weight categories in each of our pairwise comparisons in our regression models. This way, any observed gap in employment and wage outcomes is more likely to be due to labor demand as opposed to labor supply. Column (3) in Table 3 shows that for overweight men, these set of variables are instrumental in reducing the significant raw gap in log reservation wages. By and large, any gaps found between overweight and health weight men are eliminated once we control for education, socio-demographic and other characteristics. For example, in column (6), it can be seen that the raw gap in log reservation wages is 0.147 , but that this is reduced to 0.06 and no longer significant once we control for our full set of characteristics. 
* Table 3 about here *

Table 4 presents estimates of the gap in outcomes between obese and healthy weight men. As with the overweight vs. healthy weight comparison for men, there are no significant gaps in labor market outcomes once education, socio-demographic and other characteristics are controlled for.

Although our sample is not representative of the German population as a whole, our results for overweight and obese men are consistent with the findings in Cawley et al. (2005) who find no correlation between weight and earnings for German men using the German Socio-Economic Panel (GSOEP).

* Table 4 about here *

For women, the raw data in Table 5 suggest that overweight women are likely to have significantly lower reservation wages than healthy weight women, the opposite of what was found for men. In addition, overweight women are also less likely than healthy weight women to be employed in wave 2, and also to have lower $\log$ hourly wages in wave 2. However, once the regression models controls for various sets of relevant characteristics (columns (5) and (6)), the conditional gaps are no longer found to be significant.

* Table 5 about here *

On the other hand, we find that there are interesting and significant conditional gaps in search and labor market outcomes for obese women. By wave 2, the model in column (5) of Table 6, which has controls for education, socio-demographic variables and personality, reveals that obese women are about 13 percentage points less likely to be employed relative to healthy weight women; they also earn on average 0.094 less in terms of log hourly wages. The finding that obese women have lower employment levels is noteworthy and surprising as obese women had relatively lower reservation wages (-0.139 log points) and made 4.66 more job applications on average. Obese women also were 12.3 percentage points more likely to participate in 
a training program and 10.2 percentage points more likely to enrol early in an active labor market program. ${ }^{9}$

If the obesity gap is due to health limitations, we expect the obesity coefficient to become smaller and insignificant once we control for health. When we control for health (column 6), the conditional gap in search intensity and participation in training and labor market programs between obese women and healthy weight women remains statistically significant. In addition, the gap in hourly wages is also still statistically significant. Although the gap in employment levels is reduced and becomes barely insignificant ( $p$-value is 0.14 ), the point estimate of the difference (0.097) remains quite large.

\section{* Table 6 about here *}

When both health and cognitive skills are controlled for, the gaps in the ALMP variables remain statistically significant but the effects on both employment and wages lose their significance (results not shown). It is possible that this lack of statistical significance could be due to small sample size as the point estimates for employment (-0.055) and log hourly wages (-0.082) are still suggestive that a gap exists. ${ }^{10}$ On the other hand, having insignificant gaps are consistent with the findings in Lundborg et al. (2010) who argue that the negative association between obesity and earnings runs mainly through obesity's association with a variety of supply side characteristics such as cognitive skills, non-cognitive skills and measures of physical fitness.

As a robustness check, we also use a matching estimator to provide estimates of the obesity gap. We focus on the results from a propensity score specification that does not include any potentially endogenous variables such as health (i.e., the specification in column (5) of the regression models).

\footnotetext{
${ }^{9}$ There were no significant differences in participation in labor market programs in wave 2 (results not shown) so it is unlikely the case that obese women were less likely to be employed in wave 2 because they were still part of a program or undertaking training.

${ }^{10}$ The results of the models including cognitive skills (based on the results from three tests on arithmetic and one test on word recall) are not shown in an additional column in Tables 3 to 6 because about 10 percent of our sample did not respond to those questions. As a result, differences in the results between models that did and did not include cognitive skills could reflect either the importance of cognitive skills or be due to non-random selection and a different sample composition. We choose not to estimate all our models on respondents with non-missing values of measures of cognitive skills in order to not further reduce our sample size.
} 
Based on kernel matching estimates using the Epanechnikov kernel and experimenting with alternative bandwidths, there appear to be no significant effects of obesity on labor market outcomes for men, and only significant results for obese women. In other words, the matching results for obese women largely reflect the regression estimates reported in column (5) of Table 6.

\section{* Table 7 about here *}

Overall, the matching estimates which do not control for health status suggest that only obese women suffer some labor market consequences. The finding that the negative consequences of obesity on labor market outcomes are greater for females than for males is consistent with the findings from other studies analysing the impact of obesity on labour market outcomes (e.g., Baum and Ford, 2004; Cawley, 2004; Harper, 2000; Morris, 2007; Sargent and Blanchflower, 1994).

\section{Conclusions}

The economics literature has focused on estimating the effects of many different forms of discrimination. Like other forms of discrimination, weight discrimination is highly dependent on public perception. It is therefore a useful exercise to carry out empirical studies on many different subgroups of the population to measure the full extent of any discrimination that might exist in society. In this paper, we examined the issue of whether obese job applicants that newly enter unemployment in Germany have different job search behaviors from non-obese applicants, whether they participate at the same rate in ALMP programs and whether they are regarded differently by employers. The thought experiment was to hold a 'beauty contest' where employers choose whom to hire first from a line up of unemployed persons. Unlike other observational studies which are generally based on obese and non-obese individuals who might already be at different points in the job ladder (e.g., household surveys), in this case, individuals all start from the same point - they are newly unemployed. In the sense that we are trying to create a hypothetical experiment whereby individuals newly entering unemployment are assigned to different weight groups, our study design might be viewed as being somewhere inbetween an experimental study and a standard observational study. 
Our results suggest that no discrimination occurs for overweight males and females. Obese men also do not appear to suffer any forms of discrimination. The only group we find in our data experiencing any possible form of labor market discrimination is obese women. Compared to healthy weight women, obese women made more job applications and engaged more in job training programs. At the same time we find some indications that they experienced worse (or at best similar) employment outcomes than healthy weight women. One possible interpretation of these results is that obese women need to search harder in order to achieve similar employment outcomes as healthy weight women. Obese women who found a job also had significantly lower wages than healthy weight women even after controlling for an extensive set of personal characteristics. Although this might partly be an empirical realization of the fact that obese women were willing to accept lower wages to begin with, it could also reflect discrimination on the part of employers.

Our data do not allow us to disentangle whether health problems amongst the obese might be the result of past discrimination, or whether obesity causes health problems. Further research on understanding the interaction between obesity, health and labor market outcomes will be useful. 


\section{References}

Abadie, A. and G. Imbens. (2008). On the failure of the bootstrap for matching estimators. Econometrica 76: 1537-1557.

Aigner, D. and G. Cain. (1977). Statistical theories of discrimination in labor markets. Industrial and Labor Relations Review 30: 175-187.

Altonji, J. and R. Blank. (1999). Race and gender in the labor market. In Ashenfelter and D. Card (Eds.), Handbook of Labor Economics, Volume 3C: 3143-3259. Amsterdam: North-Holland.

Andreyeva T, R. Puhl and K. Brownell. (2008). Changes in perceived weight discrimination among Americans: 1995-1996 through 2004-2006. Obesity 16: 1129-1134.

Angrist, J. and J. Pischke. (2008). Mostly Harmless Econometrics: An Empiricist's Companion. New Jersey: Princeton University Press.

Averett, S. and S. Korenman. (1996). The economic reality of the beauty myth. Journal of Human Resources 31:304- 330.

Averett, S. and S. Korenman (1999). Black-white differences in social and economic consequences of obesity. International Journal of Obesity 23: 166-173.

Baum, C. and W. Ford. (2004). The wage effects of obesity: a longitudinal study. Health Economics 13: 885-899.

Becker, G. (1957). The Economics of Discrimination. Chicago: University of Chicago Press.

Berghöfer, A., T. Pischon, T. Reinhold, C. Apovian, A. Sharma and S. Willich. (2008). Obesity prevalence from a European perspective: a systematic review. BMC Public Health 8: 200 (doi:10.1186/1471-2458-8-200).

Blinder, A. (1973). Wage discrimination: Reduced form and structural estimates. Journal of Human Resources 8: 436-455.

Brunello, G. and B. D’Hombres. (2007). Does body weight affect wages? Evidence from Europe, Economics and Human Biology 5: 1-19.

Brunello, G., P. Michaud and A. Sanz-de-Galdeano. (2009). The rise of obesity in Europe: an economic perspective, Economic Policy 57: 553-596.

Burkhauser, R. and J. Cawley. (2008). Beyond BMI: the value of more accurate measures of fatness and obesity in social science research. Journal of Health Economics 27: 519-529.

Caliendo, M., A. Falk, L. Kaiser, H. Schneider, A. Uhlendorff, G. Van den Berg and K. Zimmermann. (2011). The IZA evaluation dataset: towards evidence-based 
labor policy-making. Discussion Paper 5400, IZA Bonn, forthcoming in International Journal of Manpower.

Caliendo, M. and S. Kopeinig. (2008): Some Practical Guidance for the Implementation of Propensity Score Matching. Journal of Economic Surveys 22: 31-72.

Card, D. J. Kluve and A. Weber. (2009). Active labor market policy evaluations: a meta-analysis. IZA Working Paper No. 4002.

Cawley, J. (2004). The impact of obesity on wages. Journal of Human Resources 39: 452-474.

Cawley, J. (2007). The labor market impacts of obesity, in Obesity, Business, and Public Policy, Z. Acs and A. Lyles (eds.). Northampton: Edward Elgar.

Cawley, J. and S. Danziger. (2005). Morbid obesity and the transition from welfare to work. Journal of Policy Analysis and Management 24: 727-743.

Cawley, J., M. Grabka and D. Lilard. (2005). A comparison of the relationship between obesity and earnings in the US and Germany. Schmollers Jahrbuch 125: 119-129.

Cawley J, J. Rizzo and K. Haas. (2007). Occupation-specific absenteeism costs associated with obesity and morbid obesity. Journal of Occupational and Environmental Medicine 49:1317-1324.

Corcoran, M., S. Danziger, and R. Tolman. (2004). Employment duration of africanamerican and white welfare recipients and the role of persistent health and mental health problems. Women and Health 39: 21-40.

Conley, D. and R. Glauber. (2006). Gender, body mass, and socioeconomic status: new evidence from the PSID, Advances in Health Economics and Health Services Research 17: 253-275.

Danziger, S., M. Corcoran, C. Heflin, A. Kalil, and J. Levine. (2000). Barriers to the employment of welfare recipients. In R. Cherry and W. Rodgers (Eds.), Prosperity for All? The Economic Boom and African-Americans, pp. 239272. New York: Russell Sage Foundation.

Eichhorst, W., and K. Zimmermann. (2007): "And then there were four...how many (and which) measures of active labor market policy do we still need?” Applied Economics Quarterly 53: 243-272.

Finkelstein E, C. Fiebelkorn and G. Wang. (2005). The costs of obesity among fulltime employees. American Journal of Health Promotion 20: 45-51.

Flegal K., M. Carroll, C. Ogden and C. Johnson. (2002). Prevalence and trends in obesity among U.S. adults, 1999-2000. Journal of the American Medical Association 288: 1723-1727. 
Flegal, K., M. Carroll, C. Ogden and L. Curtin. (2010). Prevalence and trends in obesity among US adults, 1999-2008. Journal of the American Medical Association 303: 235-241.

Frölich, M. (2007). Propensity score matching without conditional independence assumption with an application to the gender wage gap in the United Kingdom. Econometrics Journal 10, 359-407.

Fryer, R. and S. Levitt. (2004). Understanding the black-white test score gap in the first two years of school. Review of Economics and Statistics 86: 447-464.

Garcia, J. and C. Quintana-Domeque. (2006). Obesity, employment and wages in Europe, Advances in Health Economics and Health Services Research 17: 187217.

Harper, B. (2000). Beauty, stature and the labour market: a British cohort study. Oxford Bulletin of Economics and Statistics 62: 771-801.

Heckman, J., H. Ichimura, and P. Todd. (1998). Matching as an econometric evaluation estimator. Review of Economic Studies 65: 261-294.

Jacobi, L. and J. Kluve. (2007). Before and after the Hartz reforms. the performance of active labour market policy in Germany. Discussion Paper 41, RWI.

Jayakody, R. and D. Stauffer. (2000). Mental health problems among single mothers: Implications for work and welfare reform. Journal of Social Issues 54: 617-634.

Johansson, E., P. Böckerman, U. Kiiskinen and M. Heliövaara. (2009). Obesity and labour market success in Finland: The difference between having a high BMI and being fat. Economics and Human Biology 7: 36-45.

Lewis, G. (1986). Union Relative Wage Effects: A Survey. Chicago: The University of Chicago Press.

Lindeboom, M., P. Lundborg and B. van der Klaauw. (2010). Assessing the impact of obesity on labor market outcomes. Economics and Human Biology 8: 309-319.

Loh, E. (1993). The economic effects of physical appearance. Social Science Quarterly 74: 420-438.

Lundborg, P., P. Nystedt and D. Rooth. (2010). No country for fat men? Obesity, earnings, skills, and health among 450,000 Swedish men. IZA Working Paper No. 4775.

Morris, S. (2007). The impact of obesity on employment. Labour Economics 14: 413433.

Neal, D. and W. Johnson. (1996). The role of premarket factors in black-white wage differences. Journal of Political Economy 104: 869-895. 
Neumark, D. (1988). Employers discriminatory behaviour and the estimation of wage discrimination. Journal of Human Resources 23: 812-860.

Nopo, H. (2008). Matching as a tool to decompose wage gaps. Review of Economics and Statistics 90: 290-299.

Oaxaca, R. (1973). Male-female wage differentials in urban labor markets. International Economic Review 14: 693-709.

Pagan, J. and A. Davila. (1997). Obesity, occupational attainment and earnings. Social Science Quarterly 78: 756-770.

Puhl R. and K. Brownell. (2001). Bias, discrimination, and obesity. Obesity Research 9: 788-905.

Register, C. and D. Williams. (1980). Wage effects of obesity among young workers. Social Science Quarterly 71: 130-141.

Riach, P. and J. Rich. (2002). Field experiments of discrimination in the market place. Economic Journal 112, F480-F518.

Roehling, M. (1999). Weight-based discrimination in employment: psychological and legal aspects. Personnel Psychology 52: 969-1016.

Roehling M., P. Roehling and S. Pichler. (2007). The relationship between body weight and perceived weight-related employment discrimination: the role of sex and race. Journal of Vocational Behavior 71: 300-318.

Roehling M., S. Pilcher, F. Oswald and T. Bruce. (2008). The effects of weight bias on job-related outcomes: a meta-analysis of experimental studies. Academy of Management Annual Meeting, Anahiem, CA.

Rooth, D. (2009). Obesity, attractiveness and differential treatment in hiring: a field experiment. Journal of Human Resources 44: 710-735.

Sargent, J. and D. Blanchflower. (1994). Obesity and stature in adolescence and earnings in young adulthood: Analysis of a british birth cohort. Archives of Pediatrics and Adolescent Medicine 148: 681-687. 
Table 1: Sample Sizes

\begin{tabular}{lcccc}
\hline & \multicolumn{2}{c}{ Full Sample } & \multicolumn{2}{c}{ Searching for Job in Wave 1 } \\
\cline { 2 - 5 } & Men & Women & Men & Women \\
\hline $18.5 \leq$ BMI $<25$ & 391 & 424 & 192 & 272 \\
$25 \leq$ BMI $<30$ & 284 & 159 & 153 & 107 \\
BMI $\geq 30$ & 109 & 90 & 56 & 59 \\
\hline Total & 784 & 673 & 401 & 438 \\
\hline
\end{tabular}

Note: People with a BMI smaller than 18.5 are excluded. We also exclude individuals with missing values in key regressors. 
Table 2: Socio-Demographic Characteristics by BMI Group

\begin{tabular}{|c|c|c|c|c|c|c|}
\hline Characteristic & $\begin{array}{c}\text { (Men) } \\
18.5 \leq \mathrm{BMI} \\
<25\end{array}$ & $\begin{array}{c}\text { (Men) } \\
25 \leq \text { BMI < } \\
30\end{array}$ & $\begin{array}{c}\text { (Men) } \\
\text { BMI } \geq 30\end{array}$ & $\begin{array}{c}\text { (Women) } \\
18.5 \leq \text { BMI } \\
<25\end{array}$ & $\begin{array}{c}\text { (Women) } \\
25 \leq \mathrm{BMI}< \\
30\end{array}$ & $\begin{array}{l}\text { (Women) } \\
\text { BMI } \geq 30\end{array}$ \\
\hline West Germany & 0.68 & 0.75 & 0.76 & 0.72 & 0.73 & 0.63 \\
\hline German citizenship & 0.96 & 0.95 & 0.94 & 0.93 & 0.96 & 0.96 \\
\hline Migration background & 0.13 & 0.14 & 0.13 & 0.17 & 0.14 & 0.12 \\
\hline Age & 31.07 & 36.32 & 38.28 & 35.70 & 38.14 & 40.92 \\
\hline Married (or cohabiting) & 0.21 & 0.36 & 0.44 & 0.43 & 0.57 & 0.54 \\
\hline One child & 0.17 & 0.13 & 0.17 & 0.22 & 0.19 & 0.23 \\
\hline Two (or more) children & 0.10 & 0.14 & 0.14 & 0.18 & 0.21 & 0.10 \\
\hline Unemplomyent benefit recipient (yes) & 0.74 & 0.79 & 0.80 & 0.71 & 0.78 & 0.70 \\
\hline Level of UB (missing=0) & 453.79 & 617.63 & 661.60 & 391.10 & 435.21 & 386.06 \\
\hline \multicolumn{7}{|l|}{ School leaving degree $($ Reference $=$ none $)$} \\
\hline Lower secondary school & 0.28 & 0.28 & 0.49 & 0.17 & 0.21 & 0.30 \\
\hline Middle secondary school & 0.36 & 0.40 & 0.28 & 0.34 & 0.47 & 0.50 \\
\hline \multicolumn{7}{|l|}{ Vocational Training (Reference = none) } \\
\hline Internal or external professional training, others & 0.63 & 0.64 & 0.66 & 0.61 & 0.73 & 0.72 \\
\hline Technical college or university degree & 0.24 & 0.27 & 0.21 & 0.32 & 0.18 & 0.18 \\
\hline \multicolumn{7}{|l|}{ Employment status before unemployment } \\
\hline Employed & 0.59 & 0.64 & 0.65 & 0.63 & 0.58 & 0.66 \\
\hline Subsidized employment & 0.04 & 0.05 & 0.11 & 0.03 & 0.04 & 0.04 \\
\hline School, apprentice, military, etc. & 0.29 & 0.21 & 0.14 & 0.16 & 0.13 & 0.12 \\
\hline Maternity leave & 0.00 & 0.00 & 0.00 & 0.10 & 0.13 & 0.08 \\
\hline Other & 0.08 & 0.10 & 0.10 & 0.08 & 0.11 & 0.10 \\
\hline
\end{tabular}




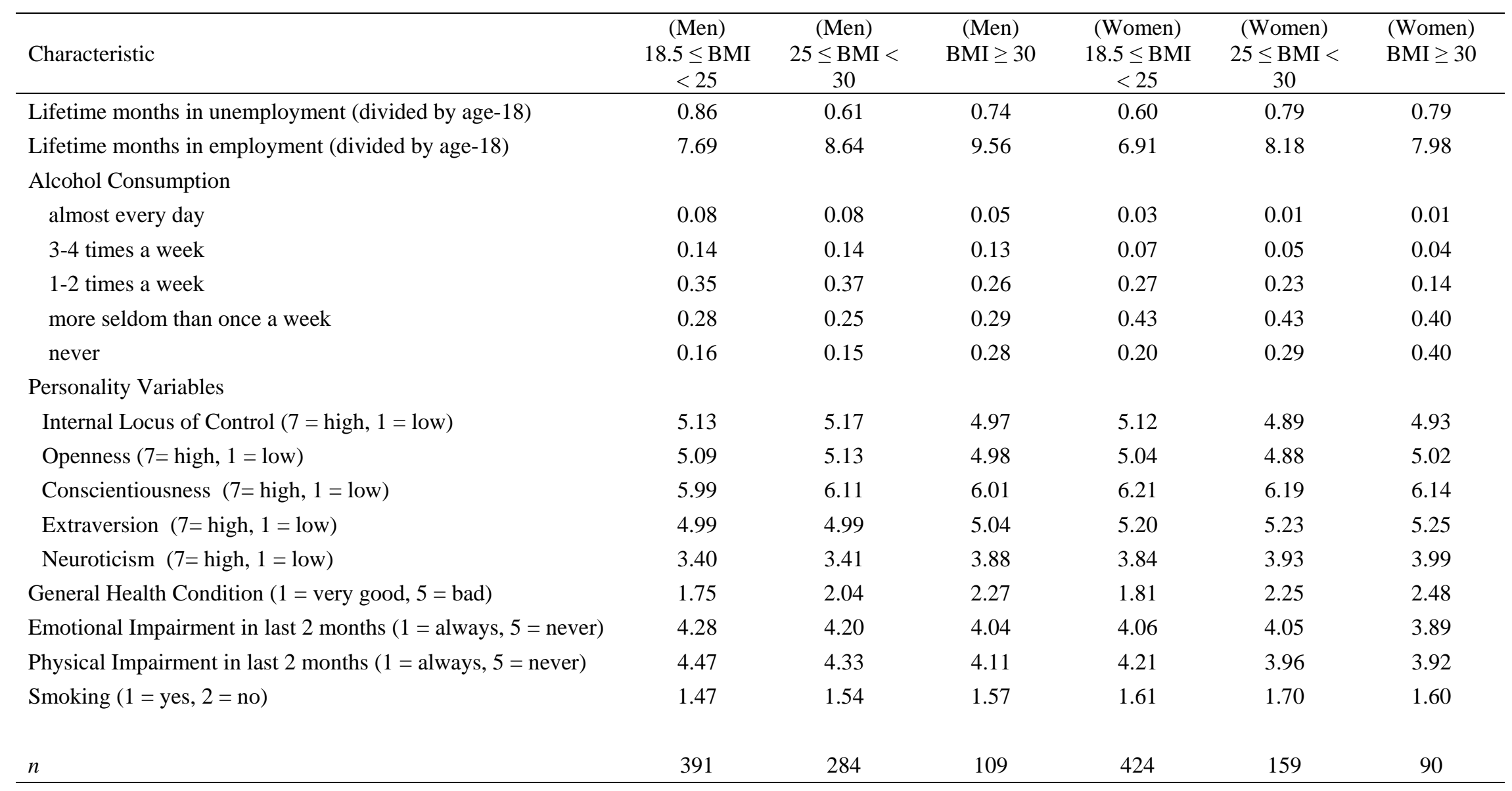


Table 3: Regression Results of Estimated Gaps: Overweight Men versus Healthy Weight Men

\begin{tabular}{|c|c|c|c|c|c|c|c|c|}
\hline Outcome Variable & $\begin{array}{l}\text { Mean for } \\
\text { Healthy } \\
\text { Weight } \\
\text { Men }\end{array}$ & Raw gap & (1) & $(2)$ & (3) & (4) & (5) & (6) \\
\hline \multicolumn{9}{|l|}{ Search Variables } \\
\hline Log Reservation Wage ${ }^{(a)}$ & 1.97 & $0.147 * * *$ & $0.115^{* * *}$ & 0.048 & $0.135^{* * *}$ & $0.144 * * *$ & 0.052 & 0.06 \\
\hline Number of Job Applications (a) & 15.29 & 1.218 & 0.708 & 1.994 & 0.753 & 1.210 & 0.936 & 0.805 \\
\hline \multicolumn{9}{|l|}{ Participation in ALMP Variables } \\
\hline Any ALMP & 0.31 & -0.014 & -0.017 & -0.033 & -0.013 & -0.017 & -0.032 & -0.037 \\
\hline Participation in Training & 0.16 & -0.008 & -0.010 & -0.007 & -0.005 & -0.014 & -0.007 & -0.014 \\
\hline Early Participation in ALMP & 0.14 & -0.018 & -0.017 & -0.016 & -0.018 & -0.022 & -0.015 & -0.022 \\
\hline \multicolumn{9}{|l|}{ Outcome Variables in Wave 2} \\
\hline Employed & 0.62 & $0.066 *$ & 0.054 & 0.029 & 0.056 & $0.081 * *$ & 0.023 & 0.033 \\
\hline Log Hourly Wages in $€^{(\mathrm{b})}$ & 2.15 & 0.069 & 0.069 & -0.025 & 0.055 & 0.063 & -0.020 & -0.025 \\
\hline Controls for education & & & $\checkmark$ & & & & $\checkmark$ & $\checkmark$ \\
\hline Controls for other demographics & & & & $\checkmark$ & & & $\checkmark$ & $\checkmark$ \\
\hline Controls for personality & & & & & $\checkmark$ & & $\checkmark$ & $\checkmark$ \\
\hline Controls for health & & & & & & $\checkmark$ & & $\checkmark$ \\
\hline$n$ & & 675 & 675 & 675 & 675 & 675 & 675 & 675 \\
\hline
\end{tabular}

Note: Significant at the: *10 percent level; **5 percent level; ***1 percent level. For the detailed list of variables in each of the categories (education, other demographics etc.), see Appendix A. We employ OLS models for the reservation wage, the number of job applications and the hourly wage. For the participation in ALMP variables and employment outcomes we use probit models and report marginal effects at the mean values of the covariates.

(a) Only observed for those who are unemployed in wave $1(n=327)$

(b) Only observed for those who are employed in wave $2(n=400)$. 
Table 4: Regression Results of Estimated Gaps: Obese Men versus Healthy Weight Men

\begin{tabular}{|c|c|c|c|c|c|c|c|c|}
\hline Outcome Variable & $\begin{array}{c}\text { Mean for } \\
\text { Healthy } \\
\text { Weight } \\
\text { Men }\end{array}$ & Raw gap & $(1)$ & $(2)$ & (3) & (4) & (5) & (6) \\
\hline \multicolumn{9}{|l|}{ Search Variables } \\
\hline Log Reservation Wage ${ }^{(a)}$ & 1.97 & 0.057 & 0.064 & -0.003 & 0.104 & 0.053 & 0.049 & 0.063 \\
\hline Number of Job Applications (a) & 15.29 & 0.868 & 0.494 & 0.987 & 0.842 & 1.306 & -0.013 & 0.479 \\
\hline \multicolumn{9}{|l|}{ Participation in ALMP Variables } \\
\hline Any ALMP & 0.31 & 0.002 & -0.009 & -0.002 & -0.003 & -0.002 & -0.005 & -0.007 \\
\hline Participation in Training & 0.16 & 0.037 & 0.022 & 0.059 & 0.015 & 0.027 & 0.021 & 0.022 \\
\hline Early Participation in ALMP & 0.14 & 0.009 & -0.002 & 0.036 & -0.011 & 0.011 & 0.007 & 0.011 \\
\hline \multicolumn{9}{|l|}{ Outcome Variables in Wave 2} \\
\hline Employed & 0.62 & -0.019 & -0.031 & $-0.120 * *$ & -0.009 & 0.03 & -0.105 & -0.078 \\
\hline Log Hourly Wages in $€^{(\mathrm{b})}$ & 2.15 & -0.007 & 0.011 & -0.078 & 0.011 & -0.008 & -0.043 & -0.061 \\
\hline Controls for education & & & $\checkmark$ & & & & $\checkmark$ & $\checkmark$ \\
\hline Controls for other demographics & & & & $\checkmark$ & & & $\checkmark$ & $\checkmark$ \\
\hline Controls for personality & & & & & $\checkmark$ & & $\checkmark$ & $\checkmark$ \\
\hline Controls for health & & & & & & $\checkmark$ & & $\checkmark$ \\
\hline$n$ & & 500 & 500 & 500 & 500 & 500 & 500 & 500 \\
\hline
\end{tabular}

Note: Significant at the: *10 percent level; **5 percent level; ***1 percent level. For the detailed list of variables in each of the categories (education, other demographics etc.), see Appendix A. We employ OLS models for the reservation wage, the number of job applications and the hourly wage. For the participation in ALMP variables and employment outcomes we use probit models and report marginal effects at the mean values of the covariates.

(a) Only observed for those who are unemployed in wave $1(n=232)$

(b) Only observed for those who are employed in wave $2(n=292)$. 
Table 5: Regression Results of Estimated Gaps: Overweight Women versus Healthy Weight Women

\begin{tabular}{|c|c|c|c|c|c|c|c|c|}
\hline Outcome Variable & $\begin{array}{c}\text { Mean for } \\
\text { Healthy } \\
\text { Weight } \\
\text { Women } \\
\end{array}$ & Raw gap & $(1)$ & (2) & (3) & (4) & (5) & (6) \\
\hline \multicolumn{9}{|l|}{ Search Variables } \\
\hline Log Reservation Wage ${ }^{(a)}$ & 1.96 & $-0.082 * *$ & -0.019 & -0.012 & $-0.078 *$ & -0.062 & -0.002 & 0.01 \\
\hline Number of Job Applications ${ }^{(a)}$ & 12.63 & 0.424 & 1.011 & 1.538 & -0.047 & 0.500 & 1.848 & 1.871 \\
\hline \multicolumn{9}{|l|}{ Participation in ALMP Variables } \\
\hline Any ALMP & 0.33 & 0.003 & -0.007 & -0.019 & 0.003 & 0.007 & -0.028 & -0.033 \\
\hline Participation in Training & 0.21 & -0.015 & -0.024 & -0.037 & -0.021 & -0.032 & -0.042 & -0.058 \\
\hline Early Participation in ALMP & 0.18 & -0.022 & -0.030 & -0.034 & -0.026 & -0.033 & -0.039 & -0.051 \\
\hline \multicolumn{9}{|l|}{ Outcome Variables in Wave 2} \\
\hline Employed & 0.70 & $-0.107 * *$ & $-0.084 *$ & -0.067 & $-0.095 * *$ & -0.064 & -0.053 & -0.015 \\
\hline Log Hourly Wages in $€^{(\mathrm{b})}$ & 2.11 & $-0.093^{*}$ & -0.016 & $-0.088 *$ & $-0.083^{*}$ & $-0.091 *$ & -0.020 & -0.021 \\
\hline Controls for education & & & $\checkmark$ & & & & $\checkmark$ & $\checkmark$ \\
\hline Controls for other demographics & & & & $\checkmark$ & & & $\checkmark$ & $\checkmark$ \\
\hline Controls for personality & & & & & $\checkmark$ & & $\checkmark$ & $\checkmark$ \\
\hline Controls for health & & & & & & $\checkmark$ & & $\checkmark$ \\
\hline$n$ & & 583 & 583 & 583 & 583 & 583 & 583 & 583 \\
\hline
\end{tabular}

Note: Significant at the: *10 percent level; **5 percent level; ***1 percent level. For the detailed list of variables in each of the categories (education, other demographics etc.), see Appendix A. We employ OLS models for the reservation wage, the number of job applications and the hourly wage. For the participation in ALMP variables and employment outcomes we use probit models and report marginal effects at the mean values of the covariates.

(a) Only observed for those who are unemployed in wave $1(n=367)$

(b) Only observed for those who are employed in wave $2(n=358)$. 
Table 6: Regression Results of Estimated Gaps: Obese Women versus Healthy Weight Women

\begin{tabular}{|c|c|c|c|c|c|c|c|c|}
\hline Outcome Variable & $\begin{array}{c}\text { Mean for } \\
\text { Healthy } \\
\text { Weight } \\
\text { Women } \\
\end{array}$ & Raw gap & $(1)$ & (2) & (3) & (4) & (5) & (6) \\
\hline \multicolumn{9}{|l|}{ Search Variables } \\
\hline Log Reservation Wage ${ }^{(a)}$ & 1.96 & $-0.214 * * *$ & $-0.148 * * *$ & $-0.163 * * *$ & $-0.212 * * *$ & $-0.187 * * *$ & $-0.139 * *$ & $-0.123^{* *}$ \\
\hline Number of Job Applications ${ }^{(a)}$ & 12.63 & $3.952 *$ & 4.179* & $4.472 * *$ & $3.762 *$ & $4.350 *$ & $4.660 * *$ & $5.200 * *$ \\
\hline \multicolumn{9}{|l|}{ Participation in ALMP Variables } \\
\hline Any ALMP & 0.33 & 0.014 & 0.015 & 0.044 & 0.018 & 0.042 & 0.05 & 0.071 \\
\hline Participation in Training & 0.21 & $0.101^{*}$ & $0.09 *$ & $0.117 *$ & $0.105^{* *}$ & $0.101^{*}$ & $0.123 * *$ & $0.123 * *$ \\
\hline Early Participation in ALMP & 0.18 & 0.076 & 0.066 & $0.099 *$ & 0.079 & 0.068 & $0.102 *$ & $0.095 *$ \\
\hline \multicolumn{9}{|l|}{ Outcome Variables in Wave 2} \\
\hline Employed & 0.70 & $-0.165 * * *$ & $-0.140 * *$ & $-0.143^{* *}$ & $-0.156 * * *$ & $-0.116^{* *}$ & $-0.132 * *$ & -0.097 \\
\hline Log Hourly Wages in $€^{(\mathrm{b})}$ & 2.11 & $-0.198 * * *$ & $-0.104^{*}$ & $-0.167 * * *$ & $-0.204 * * *$ & $-0.164 * * *$ & $-0.094^{*}$ & $-0.092 *$ \\
\hline Controls for education & & & $\checkmark$ & & & & $\checkmark$ & $\checkmark$ \\
\hline Controls for other demographics & & & & $\checkmark$ & & & $\checkmark$ & $\checkmark$ \\
\hline Controls for personality & & & & & $\checkmark$ & & $\checkmark$ & $\checkmark$ \\
\hline Controls for health & & & & & & $\checkmark$ & & $\checkmark$ \\
\hline$n$ & & 514 & 514 & 514 & 514 & 514 & 514 & 514 \\
\hline
\end{tabular}

Note: Significant at the: *10 percent level; **5 percent level; ***1 percent level. For the detailed list of variables in each of the categories (education, other demographics etc.), see Appendix A. We employ OLS models for the reservation wage, the number of job applications and the hourly wage. For the participation in ALMP variables and employment outcomes we use probit models and report marginal effects at the mean values of the covariates.

(a) Only observed for those who are unemployed in wave $1(n=321)$

(b) Only observed for those who are employed in wave $2(n=320)$. 
Table 7: Matching Estimates of the Gap for Men and Women

\begin{tabular}{lcccc}
\hline Outcome & Kernel & Kernel & Kernel & \\
Matching & Matching & Matching & $n$ for Treated & $n$ for Control \\
& $(\mathrm{bw}=0.02)$ & $(\mathrm{bw}=0.06)$ & $(\mathrm{bw}=0.2)$ & \\
\hline
\end{tabular}

\section{a) Overweight Men versus Healthy Weight Men}

$\begin{array}{lccccr}\text { Log Reservation Wage } & 0.065 & 0.072 & 0.085^{*} & 146 & 181 \\ \text { Number of Job Applications } & 0.821 & 0.815 & 1.001 & 144 & 180 \\ \text { Any ALMP } & -0.020 & -0.024 & -0.023 & 284 & 391 \\ \text { Participation in Training } & -0.001 & 0.001 & -0.003 & 284 & 391 \\ \text { Early Participation in ALMP } & -0.021 & -0.018 & -0.018 & 284 & 391 \\ \text { Employed in Wave 2 } & -0.001 & 0.011 & 0.019 & 284 & 391 \\ \text { Log Hourly Wages at Wave 2 } & -0.026 & -0.015 & 0.008 & 176 & 224\end{array}$

b) Obese Men versus Healthy Weight Men

$\begin{array}{lccccr}\text { Log Reservation Wage } & 0.017 & 0.021 & -0.001 & 51 & 181 \\ \text { Number of Job Applications } & 1.382 & -0.942 & 1.170 & 51 & 180 \\ \text { Any ALMP } & 0.015 & 0.018 & 0.008 & 109 & 391 \\ \text { Participation in Training } & 0.052 & 0.064 & 0.056 & 109 & 391 \\ \text { Early Participation in ALMP } & 0.023 & 0.034 & 0.028 & 109 & 391 \\ \text { Employed in Wave 2 } & -0.075 & -0.078 & -0.059 & 109 & 391 \\ \text { Log Hourly Wages at Wave 2 } & -0.111 & -0.068 & -0.038 & 68 & 224\end{array}$

c) Overweight Women versus Healthy Weight Women

$\begin{array}{lccccc}\text { Log Reservation Wage } & -0.012 & -0.008 & -0.023 & 104 & 263 \\ \text { Number of Job Applications } & 0.845 & 0.935 & 1.044 & 103 & 260 \\ \text { Any ALMP } & 0.005 & -0.005 & -0.008 & 159 & 424 \\ \text { Participation in Training } & -0.019 & -0.031 & -0.028 & 159 & 424 \\ \text { Early Participation in ALMP } & -0.025 & -0.033 & -0.033 & 159 & 424 \\ \text { Employed in Wave 2 } & -0.069 & -0.063 & -0.067 & 159 & 424 \\ \text { Log Hourly Wages at Wave 2 } & -0.047 & -0.052 & -0.067 & 87 & 271\end{array}$

d) Obese Women versus Healthy Weight Women

Log Reservation Wage

Number of Job Applications

Any ALMP

Participation in Training

Early Participation in ALMP

Employed in Wave 2

Log Hourly Wages at Wave 2

$\begin{array}{cc}-0.140^{*} & -0.125 \\ 5.220 & 4.993 \\ 0.088 & 0.073 \\ 0.159 * * * & 0.145^{* * *} \\ 0.131^{* *} & 0.122^{* *} \\ -0.106 & -0.104 \\ -0.128^{*} & -0.119^{* *}\end{array}$

$-0.134^{* *}$

4.719*

0.055

$0.130 * *$

$0.109 * *$

$-0.118 *$

$-0.126^{* *}$
256

253

424

424

424

424

271

Note: Propensity score models are estimated using the full set of covariates used in Model 5 of the regression results. Matching is performed using the Epanechnikov kernel. Common support is imposed using the min-max criterion. Imposing common support using 5\% trimming resulted in similar results and is not shown. Standard errors are based on bootstrapping with 100 replications. Significant at the: *10 percent level; **5 percent level; ***1 percent level. 


\section{Appendix A}

List of variables used in the regression models in Tables 3-6:

Education variables:

Other demographic variables:

Personality variables:

Health variables: school leaving degree (none, lower secondary, middle secondary, specialized secondary), vocational training (professional training, technical college or university degree).

West Germany, citizenship, married, number of children $(0,1,2+)$, unemployment benefit recipient, level of benefits, age (17-24, 25-34, 35-44, 45-55), lifetime months in unemployment, lifetime months in employment, month of entry into unemployment, employment status before unemployment (employed, subsidized employment, school/apprentice/military, maternity leave, other), local unemployment rate (<5\%, 5-10\%, 10-15\%,15+\%), alcohol consumption (almost every day, 3-4 times a week, 1-2 times a week, more seldom than once a week, never).

openness, conscientiousness, extraversion, neuroticism, internal locus of control index.

general health condition (1=very good, 5=bad), emotional impairment in last 2 months (1=always, $5=$ =never), physical impairment in last 2 months (1=always, $5=$ never), smoking. 